\title{
p53 negatively regulates intestinal immunity by delaying mucosal $T$ cell cycling
}

\author{
Andreas Sturm, ${ }^{1}$ Jugoh Itoh, ${ }^{1}$ James W. Jacobberger, ${ }^{2}$ and Claudio Fiocchi ${ }^{1}$ \\ ${ }^{1}$ Division of Gastroenterology, Department of Medicine, and \\ ${ }^{2}$ Ireland Cancer Research Center, University Hospitals of Cleveland, Case Western Reserve University School of Medicine, \\ Cleveland, Ohio, USA \\ Address correspondence to: Claudio Fiocchi, Division of Gastroenterology, University Hospitals of Cleveland, \\ Case Western Reserve University School of Medicine (BRB 425), 10900 Euclid Avenue, Cleveland, Ohio 44106-4952, USA. \\ Phone: (216) 368-1668; Fax: (216) 368-1674; E-mail: cxf18@ po.cwru.edu.
}

Received for publication January 3, 2002, and accepted in revised form May 1, 2002.

To mount an effective immune response, $\mathrm{T}$ cells must divide in response to antigen contact. To maintain tolerance, mucosal lamina propria T cells (LPTs) may adapt their cycling to an antigen-rich gut stimulatory environment. Here, we compared the cell cycle kinetics of LPTs and peripheral blood T cells (PBTs) before and after CD3- and CD2-mediated activation. While CD3-activated naive $\left(\mathrm{CD}_{5} \mathrm{RA}^{+}\right)$and memory $\left(\mathrm{CD}^{2} \mathrm{RO}^{+}\right)$PBTs peaked in the $\mathrm{S}$ and $\mathrm{G} 2 / \mathrm{M}$ phase at $2-3$ days, CD3-activated LPTs peaked at 4-6 days. In contrast, CD2 activation induced modest PBT but vigorous LPT cycling. The doubling time of CD3-activated PBTs was 1 day, while that of CD3-or CD2-activated LPTs was 2 days. LPTs failed to upregulate cyclin-dependent kinase 4 and cyclin D3, but Rb phosphorylation and cyclin A and B1 upregulation were induced by CD2 engagement. The extents of clonal expansion in LPT and PBT were comparable, indicating that LPTs' slow replication delays but does not hinder cell division. CD2-activated LPTs displayed a striking upregulation of $\mathrm{p} 53$, whose blockade by antisense oligonucleotides accelerated their $\mathrm{S}$ phase transit time to that of CD3-activated PBTs. By slowing LPT cycling, p53 may act as a negative regulator of mucosal immunity, promoting immunological tolerance by preventing excessive $T$ cell replication.

J. Clin. Invest. 109:1481-1492 (2002). doi:10.1172/JCI200214967.

\section{Introduction}

All cells must meet the challenge of coordinating a complex series of events needed to successfully replicate their DNA and undergo cell division so they can optimally function and survive in their respective organs $(1,2)$. Tissue-specific immune cells must respond to antigens in a selective and balanced fashion that allows them to mount an effective response by progressing through the cell cycle, clonally expanding, and undergoing apoptosis once the antigen has been cleared $(3,4)$. This task is particularly challenging for $\mathrm{T}$ cells exposed to antigens that are numerous and that vary in type, as in the gastrointestinal tract. In the intestinal mucosa, $\mathrm{T}$ cells are required to maintain a state of immunological tolerance toward a myriad of dietary and bacterial antigens (5-8). To accomplish this critical assignment, intestinal $\mathrm{T}$ cells may cycle differently from systemically circulating $\mathrm{T}$ cells, such as peripheral blood $\mathrm{T}$ cells (PBTs), which encounter a completely different antigen repertoire $(6,9,10)$. Current knowledge of human $\mathrm{T}$ cell cycle kinetics is restricted to PBTs, and no information is available on the kinetics of tissue-localized cells such as intestinal $\mathrm{T}$ cells, a population of highly differentiated memory cells $(10,11)$. In spite of their differentiation state, they display a small size, do not spontaneously proliferate, and have a low metabolic rate, all these being characteristics of quiescent $T$ cells (12). Lamina propria $T$ cells (LPTs) proliferate uniquely in response to activation of the CD3 and CD2 pathways $(13,14)$, and, since apoptosis depends on the state of cell differentiation (15), LPTs are more susceptible to apoptosis than PBTs (16). Because both proliferation and apoptosis are intimately linked to the cell cycle (15), LPT cycling may display distinctive features that explain how these highly differentiated memory cells maintain long-term quiescence in the gut mucosa.

Cell cycle regulation is mediated by a large number of molecules that work in coordination to establish a balance among stimulatory and inhibitory signals (15, 17-19). Orderly progression of the cell cycle is positively controlled by periodic activation of cyclin-dependent kinase (CDK) complexes, and negatively controlled by the phosphorylation of CDKs and the expression of peptide CDK inhibitors that prevent uncontrolled proliferation (19). In addition, the replication machinery requires the activity of telomerase, a specific enzyme that extends DNA length and permits sustained replication $(20,21)$. Cell proliferation is linked to apoptosis by stress-integrating proteins, such as $\mathrm{p} 53$, that have the dual capacity of ensuring the proper execution of the cell cycle program but also promoting cell death when genomic damage occurs $(22,23)$.

We investigated whether LPTs, which are largely responsible for maintenance of normal immune reactivity in the intestine, display peculiar features of cell 
cycle regulation that underlie their specific adaptation to the antigen-rich mucosal environment. A detailed analysis of population and cell cycle kinetics, expression of cell cycle regulatory molecules, telomerase activity, and clonal expansion of LPTs was performed and compared with a similar analysis of PBTs. The results revealed that LPTs display unique growth kinetics characterized by a slower cell cycle controlled by endogenously high levels of p53, generate lower telomerase activity, but retain the capacity to mount a vigorous clonal expansion.

\section{Methods}

Reagents and antibodies. For $\mathrm{T}$ cell isolation, the mucosa strips were digested in collagenase type $3(206 \mathrm{U} / \mathrm{mg})$ and deoxyribonuclease type $1(3228 \mathrm{U} / \mathrm{mg})$, both from Worthington Biochemical Corp. (Lakewood, New Jersey, USA). Recombinant human IL-2 (Chiron Corp., Emeryville, California, USA) and mAb's to CD3 (OKT3; Ortho Diagnostic Systems Inc., Raritan, New Jersey, USA), CD2 (T11 2 and $\mathrm{T} 11_{3}$; generously provided by Ellis Reinherz, Dana Farber Cancer Institute, Boston, Massachusetts, USA), and CD28 (ANC28.1/5D10; Ancell Corp., Bayport, Minnesota, USA) were used for $\mathrm{T}$ cell activation. FITC-conjugated cyclin $\mathrm{B} 1$ and bromodeoxyuridine (BrdU) were purchased from BD Pharmingen (San Diego, California, USA), anti-phospho-histone $\mathrm{H} 3$ antibody was obtained from Upstate Biotechnology Inc. (Lake Placid, New York, USA), and secondary Alexa Fluor 350-labeled goat anti-rabbit IgG was obtained from Molecular Probes Inc. (Eugene, Oregon, USA). The Vybrant CFDA SE Cell Tracer Kit was also obtained from Molecular Probes Inc. Propidium iodide (PI) was purchased from Calbiochem-Novabiochem Corp. (San Diego, California, USA). All protease and phosphatase inhibitors used for Western blotting and rhodamine123 were purchased from Sigma-Aldrich (St. Louis, Missouri, USA). The antibodies against CDK4 and cyclin D2 were obtained from Santa Cruz Biotechnology Inc. (Santa Cruz, California, USA), and those against human cyclin D3, retinoblastoma protein, p130 (Rb2), p107, cyclins A and B1, p21, and p27 were obtained from BD Pharmingen. The ribonuclease protection assay hcc- 1 was also obtained from BD Pharmingen. Nocodazole was purchased from Biomol Research Laboratories (Plymouth Meeting, Pennsylvania, USA).

Isolation of $T$ lymphocytes from intestinal lamina propria and peripheral blood. Intestinal $\mathrm{T}$ cells were isolated from surgical specimens obtained from patients admitted for bowel resection for malignant or nonmalignant conditions including colon cancer, benign polyps, rectal prolapse, and diverticulosis. All specimens were histologically normal. LPTs were isolated as previously described (24). Briefly, the dissected intestinal mucosa was freed of mucus and epithelial cells in sequential washing steps with DTT and EDTA, and digested overnight at $37^{\circ} \mathrm{C}$ with collagenase and deoxyribonuclease. Mononuclear cells were separated from the crude cell suspension by layering on a Ficoll-Hypaque density gradient. If necessary, further purification was archived by subsequent Percoll density gradients. For LPT purification, macrophage-depleted lamina propria mononuclear cells were incubated for 30 minutes at $4^{\circ} \mathrm{C}$ with magnetically labeled anti-CD19, -CD14, and -CD16 antibodies directed against B lymphocytes, monocytes, and neutrophils, respectively (Miltenyi Biotec Inc., Auburn, California, USA). T cells were then collected by negative selection using a magnetic cell sorting system (MACS; Miltenyi Biotec Inc.).

PBTs were isolated from heparinized venous blood of healthy volunteers using a Ficoll-Hypaque density gradient and were monocyte-depleted. For isolation of naive $\left(\mathrm{CD}^{2} 5 \mathrm{RA}^{+}\right)$and memory $\left(\mathrm{CD} 45 \mathrm{RO}^{+}\right)$PBTs, PBMCs were submitted to the same process of negative selection described for LPTs, in combination with CD45RO antibodies to select the CD45RA ${ }^{+}$population, or CD45RA antibodies to select the $\mathrm{CD}^{2} 5 \mathrm{RO}^{+}$ population. CD45RA and CD45RO antibodies were from Miltenyi Biotec Inc.

As assessed by flow cytometry, the purified LPT and PBT populations contained $>92 \%$ and $>95 \% \mathrm{CD}^{+}$cells, respectively. LPTs were $91 \% \mathrm{CD}^{4} 5 \mathrm{RO}^{+}$, and PBTs were $54 \%$ naive T cells $\left(\mathrm{CD} 45 \mathrm{RA}^{+}\right)$. The CD45RO-depleted PBT population was >98\% CD $45 \mathrm{RA}^{+}$and less than $2 \%$

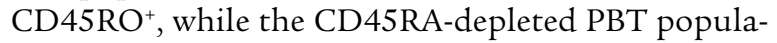

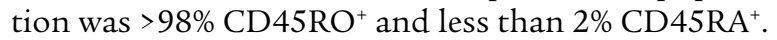

Cells were cultured in complete medium (RPMI 1640, $10 \%$ FCS, 1.5\% HEPES buffer, $2.5 \%$ penicillin-streptomycin; all from BioWhittaker Inc., Walkersville, Maryland, USA) for 3 days in a humidified incubator containing $5 \% \mathrm{CO}_{2}$, alone or in the presence of cross-linked plate-bound anti-CD3 mAb (OKT3; $10 \mu \mathrm{g} / \mathrm{ml})$ or soluble anti-CD2 $\mathrm{mAb}$ pairs $\left(\mathrm{T} 11_{2}\right.$ and $\left.\mathrm{T} 11_{3} ; 1: 1000\right)$. PI content, telomerase activity, and clonal expansion of PBTs submitted to the protocol used for LPTs were comparable to those of freshly isolated PBTs.

Flow cytometry. Cell fluorescence was measured with the Elite ESP and Epics XL flow cytometers (Beckman Coulter Inc., Miami, Florida, USA) using ultraviolet and/or 488-nm excitation and band pass filters optimized for individual fluorochromes. Flow cytometry data were analyzed with WinList (Verity Software House Inc., Topsham, Maine, USA).

Analysis of cell cycle phase distribution. Flow cytometry was performed after staining for DNA content, cyclin $\mathrm{B} 1$, and mitotic cells essentially as previously described (25). Briefly, cells were washed twice with PBS, adjusted to $1 \times 10^{6}$ cells per sample, and fixed in $90 \%$ methanol at $-20^{\circ} \mathrm{C}$. After fixation, cells were washed twice with PBS and incubated with a polyclonal rabbit anti-phospho-histone $\mathrm{H} 3$ antibody for 45 minutes at $4^{\circ} \mathrm{C}$, followed by an incubation with a goat anti-rabbit Alexa Fluor 350 antibody for 45 minutes at $4^{\circ} \mathrm{C}$. Thereafter cells were washed and incubated for 45 minutes at $4^{\circ} \mathrm{C}$ with a cyclin $\mathrm{B} 1$ FITC-conjugated $\mathrm{mAb}$. After the final wash, cells were resuspended in PBS and $5 \mu$ of RNase $(0.6 \mu \mathrm{g} / \mathrm{ml}, 30-60$ Kunitz units; Sigma-Aldrich), 
incubated at $37^{\circ} \mathrm{C}$ for 15 minutes, and then chilled on ice. One hundred twenty-five microliters of PI (200 $\mu \mathrm{g} / \mathrm{ml}$ ) were added prior to analysis by flow cytometry. Each analysis was performed on at least 25,000 events.

Cell surface staining for phenotypic analysis. Cell phenotype was analyzed using mAb's conjugated to CD45RA-R-phycoerythrin (CD45A-RPE), CD45ROFITC, and CD3-RPE (all from DAKO Corp., Carpinteria, California, USA). The background level of immunofluorescence was determined by incubating cells with FITC- or RPE-conjugated mouse IgG. After 30 minutes' incubation on ice, cells were washed twice in $1 \%$ BSAPBS and fixed in $1 \%$ paraformaldehyde. Each analysis was performed on at least 10,000 events.

Analysis of cell division. Analysis of cell division by dye dilution was performed using the Vybrant CFDA SE Cell Tracer Kit. Cells were washed twice with cold PBS, resuspended in PBS with $5 \mu \mathrm{M}$ carboxyfluorescein diacetate succinimidyl ester (CFDA SE) per $1 \times 10^{6}$ cells, and incubated for 15 minutes at $4^{\circ} \mathrm{C}$ in the dark. The staining was quenched by adding $5 \times$ cell culture medium containing $10 \%$ FCS. After staining, cells were cultured alone (unstimulated), or with soluble anti-CD2 $\mathrm{mAb}$ pairs $\left(\mathrm{T} 11_{2}\right.$ and $\left.\mathrm{T} 11_{3} ; 1: 1000\right)$ or cross-linked platebound anti-CD3 $\mathrm{mAb}(\mathrm{OKT} 3 ; 10 \mu \mathrm{g} / \mathrm{ml})$, each with CD28 $(5 \mu \mathrm{g} / \mathrm{ml})$ and IL-2 $(20 \mathrm{U} / \mathrm{ml})$. After 4 days, cells were harvested, washed twice in cold PBS, fixed with $1 \%$ paraformaldehyde, and analyzed by flow cytometry.

Measurement of DNA synthesis time, potential doubling times, G2/M enter fractions, and tritiated thymidine uptake. Analysis of cell kinetics was performed using two-color flow cytometric techniques relying on $S$ phase labeling with BrdU or stathmokinetic experiments relying on the accumulation of cells in the $\mathrm{M}$ phase by nocodazole. For the determination of $\mathrm{S}$ phase duration and potential doubling times, cells were grown for 3 days with or without the respective stimuli and then incubated for 60 minutes with $20 \mu \mathrm{M}$ BrdU, which was then replaced by thymidine. At designated time points, cells were harvested and fixed with $90 \%$ methanol. The BrdU-labeled nuclei were then stained with an FITCconjugated $\mathrm{mAb}$ against $\mathrm{BrdU}$ (BD Pharmingen). The nuclei were also stained with PI following the abovementioned protocols. The denaturation of DNA allowing antibody binding to the incorporated BrdU was achieved by an acid treatment using a previously described protocol (26). Mathematical analysis was performed according to the methods of Begg et al. (27) and White et al. (28). The movement of BrdU-labeled cells across $\mathrm{S}$ phase relative to the position of $\mathrm{G} 1$ and $\mathrm{G} 2+\mathrm{M}$ was calculated by

\section{Equation 1}

$$
R M(t)=\frac{F_{S(t)}-F_{G 1(t)}}{F_{G 2+M(t)}-F_{G(t)}}
$$

where $\mathrm{RM}=$ relative movement, $\mathrm{F}_{\mathrm{G} 1}=$ unlabeled $\mathrm{G} 1$ mean red fluorescence, $\mathrm{F}_{\mathrm{G} 2+\mathrm{M}}=$ unlabeled $\mathrm{G} 2+\mathrm{M}$ mean red fluorescence, and $\mathrm{F}_{\mathrm{S}}=$ mean red fluorescence of the
BrdU-labeled cells at time $t$. S phase duration $\left(\mathrm{T}_{\mathrm{S}}\right)$ was calculated as the time for one unit relative movement. The potential doubling time was computed by

\section{Equation 2}

$$
\mathrm{T}_{\text {pot }}=\ln (2) \mathrm{T}_{\mathrm{s}} / V
$$

with $v$ defined as $\ln \left[1+\mathrm{f}^{\mathrm{lu}}(\mathrm{t}) / 1-\mathrm{f}^{\mathrm{ld}}(\mathrm{t}) / 2\right]$, where $\mathrm{f}^{\mathrm{lu}}(\mathrm{t})=$ fraction of labeled, undivided cells at time $t$, and $\mathrm{fld}^{\mathrm{ld}}(\mathrm{t})=$ fraction of labeled, divided cells at time $t$.

Cells were incubated with or without the respective stimulus for 3 days. Mitosis was then inhibited by adding $100 \mathrm{ng} / \mathrm{ml}$ nocodazole. At timed intervals, cells were harvested and fixed for flow cytometric analysis. The G2/M enter rates were calculated as the percentage of cells that left or entered the respective cell cycles at the designated time points. These experiments were complemented by measurement of tritiated thymidine uptake as previously described (14).

Assessment of energy consumption by determining mitochondrial polarization status. Rhodamine 123 is a fluorescent cationic dye that accumulates in the mitochondrial matrix because of its charge and solubility in both the inner mitochondrial membrane and matrix space (29). Based on the observation that accumulation of this lipophilic dye is in proportion to $\Delta \Psi$, oxygen consumption, and ATP production (30) and that de-energizing of the mitochondria decreases rhodamine 123 fluorescence (31), we measured the mitochondrial membrane potential of PBTs and LPTs. Cells were stimulated with $\mathrm{CD} 2$ or $\mathrm{CD} 3$ for 4 days, harvested, washed, and resuspended in $1 \mathrm{ml}$ of rhodamine $123(10 \mu \mathrm{g} / \mathrm{ml})$ for 30 minutes at $37^{\circ} \mathrm{C}$ in the dark. The samples were washed twice in cold PBS, and fluorescence analysis by flow cytometry using an argon ion laser with an emission filter at $530 \mathrm{~nm}$ was performed immediately without fixation. PBTs and LPTs without stimulation and unstained samples were used as controls.

Western blotting. Treated cells were washed twice in cold PBS and lysed in cell lysis buffer (1\% Triton X, 0.5\% NP-40, $0.1 \%$ SDS, $0.5 \%$ sodium deoxycholate, $5 \mathrm{mM}$ EDTA, $50 \mathrm{mM}$ phosphatase and $50 \mathrm{mM}$ protease inhibitor cocktail, $1 \mathrm{mM}$ PMSF, $100 \mu \mathrm{g} / \mathrm{ml}$ trypsin-chymotrypsin inhibitor, and $100 \mu \mathrm{g} / \mathrm{ml}$ chymostatin in PBS). The concentration of proteins in each lysate was measured using the Bio-Rad protein assay (Bio-Rad Laboratories Inc., Hercules, California, USA). Equivalent amounts of protein $(10 \mu \mathrm{g})$ were fractionated on a 4-20\% Tris-glycine gel and electrotransferred to a Nitrocellulose membrane (Novex, San Diego, California, USA). Membranes were blocked overnight at $4^{\circ} \mathrm{C}$ with $5 \%$ milk in $0.1 \%$ Tween-20-PBS (Fisher Scientific Co., Hanover Park, Illinois, USA), followed by incubation for 60 minutes at room temperature with the indicated primary antibody. The membranes were washed six times with $0.1 \%$ Tween-20-PBS and then incubated for 1 hour with the appropriate horseradish peroxidase-conjugated secondary antibody (Santa Cruz Biotechnology Inc.), 
washed again, and incubated with chemiluminescent substrate (Super Signal; Pierce Chemical Co., Rockford, Illinois, USA) for 5 minutes. The membranes were then exposed to film (Amersham Life Sciences Inc., Arlington Heights, Illinois, USA). The level of individual proteins in each band was measured by densitometry and expressed as arbitrary densitometry units normalized to their respective GAPDH. This allows comparison within one protein, but not between proteins.

$R N A$ preparation and RNase protection assay. Total RNA was extracted using the guanidinium thiocyanate method (32). The RNase protection assay for quantification of cell cycle regulator (CDKs 1-4, p27, p21, PISSLRE, and p16) mRNA was performed according to the manufacturer's instructions (BD Pharmingen). Briefly, a human cell cycle regulator multiprobe template set (hcc-1) was labeled with $\alpha_{-}{ }^{32} \mathrm{P}$ uridine triphosphate (NEN Life Science Products Inc., Boston, Massachusetts, USA). Five micrograms of total RNA were hybridized with the $\alpha-{ }^{32} \mathrm{P}$ labeled probe. The remaining RNA was digested, and the extracted product was resolved on a $0.4-\mathrm{mm} 4 \%$ urea-polyacrylamide gel. The signal was analyzed using a phosphoimaging system for quantification (Bio-Rad Laboratories Inc.). GAPDH and L32 were used as internal control to normalize for loading differences.

Measurement of telomerase activity. Telomerase activity was measured using a photometric enzyme immunoassay for quantitative determination of telomerase activity (Telo TAGG Telomerase PCR ELISA; Roche Diagnostics $\mathrm{GmbH}$, Mannheim, Germany) based on the telomeric repeat amplification protocol (TRAP) method described by Kim and Wu (33). $2 \times 10^{5}$ cells were lysed, incubated on ice for 20 minutes, and then centrifuged at $16,000 \mathrm{~g}$ for 20 minutes at $4^{\circ} \mathrm{C}$. The TRAP was performed according to the manufacturer's instructions. Briefly, telomeric repeats were added to a biotin-labeled primer during the first reaction. The elongation products were amplified by PCR. An aliquot of PCR product was denatured, hybridized to a digoxigenin-labeled, telomeric repeat-specific probe, and bound to a streptavidin-coated 96-well plate. An antibody to digoxigenin, conjugated to peroxidase, was subsequently added, and binding to digoxigenin was visualized by virtue of the ability of the enzyme to metabolize tetramethyl benzidine to produce a colored reaction product. The absorbance of the samples was measured at $450 \mathrm{~nm}$ (reference wavelength $690 \mathrm{~nm}$ ) using a microplate reader (Bio-Tek Instruments Inc., Winooski, Vermont, USA) within 30 minutes after addition of the stop reagent. Mean OD values were recorded as relative telomerase activity. The immortalized human kidney cell line 293 was used as positive control. Inactivation of telomerase protein at $85^{\circ} \mathrm{C}$ for 10 minutes was used as negative control. For the generation of the telomeric-mediated six-nucleotide ladder, cell lysates were prepared and amplified as described above. One-third of the amplified products (1000 cell equivalents) were then separated on a $12 \%$

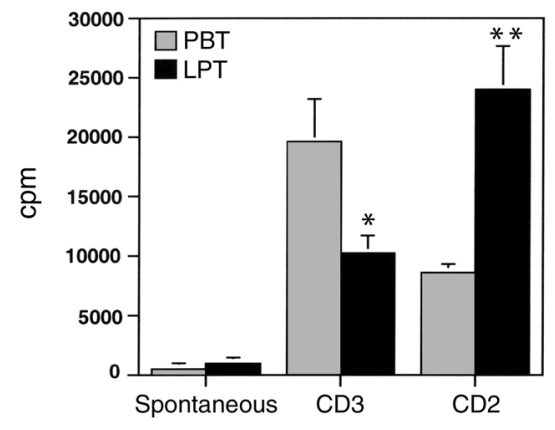

\section{Figure 1}

Differential proliferation of PBTs and LPTs in response to anti-CD3 and anti-CD2 stimulation. PBTs and LPTs were cultured in the absence and presence of immobilized anti-CD3 mAb or soluble anti$\mathrm{CD} 2\left(\mathrm{~T} 11_{2}\right.$ and $\left.\mathrm{T} 11_{3}\right) \mathrm{mAb}$ for 72 hours, and pulsed with ${ }^{3} \mathrm{H}$ thymidine for the last 18 hours, prior to harvesting and counting in a beta counter. Data are expressed as mean \pm SE of eight separate experiments. ${ }^{*} P<0.05,{ }^{*} P<0.005$.

nondenaturing polyacrylamide gel and stained with SYBR green I nucleic acid stain (Molecular Probes Inc.). p53 oligodeoxynucleotides and transfection protocol. Phosphorothioate p53 antisense oligonucleotide ( $5^{\prime}$-CCCTGCTCCCCCCTGGCTCC-3') and scrambled control ( $5^{\prime}$ CGGTGATCTCCAGAGTATGC-3') oligonucleotides as negative control were obtained from CalbiochemNovabiochem Corp. $(34,35)$. Transfection was performed using cationic lipopolyamines, which have been shown to ensure an efficient transport of oligonucleotides in eukaryotic cells (36). Briefly, in every experiment $20 \times 10^{6}$ PBTs or LPTs were washed and then resuspended in $10 \mathrm{ml}$ Opti-MEM medium (Invitrogen Corp., Carlsbad, California, USA) containing $1 \mu \mathrm{l} / \mathrm{ml}$ Oligofectamine (Invitrogen Corp.) premixed with the p53 or scrambled control antisense at a final concentration of $4 \mu \mathrm{g} \mathrm{DNA} / \mathrm{ml}$. After a $4-$ hour incubation at $37^{\circ} \mathrm{C}$ and $5 \% \mathrm{CO}_{2}, 5 \mathrm{ml}$ of growth medium containing 30\% FCS was added and cells were stimulated for 3 days as described. Samples incubated with Oligofectamine or antisense alone and nontransfected cells were used as controls.

Statistical analysis. Statistical analysis was performed using the Student's $t$ test. Results are expressed as mean \pm SEM, and significance was inferred with $P$ values less than 0.05 .

\section{Results}

Distinct cell cycle kinetics of PBTs and LPTs. Differences in PBT and LPT proliferation in response to stimulation of the CD3 and CD2 pathways have been largely defined based on results of tritiated thymidine uptake $(10,13,14,37)$. Using this method, we confirmed this differential reactivity by showing that LPTs displayed a significantly reduced proliferation in response to a 3-day anti-CD3 stimulation $(P<0.05)$ and enhanced proliferation in response to a 3 -day anti-CD2 stimulation $(P<0.005)$ compared with equally stimulated PBTs (Figure 1). Although simple and reproducible, 


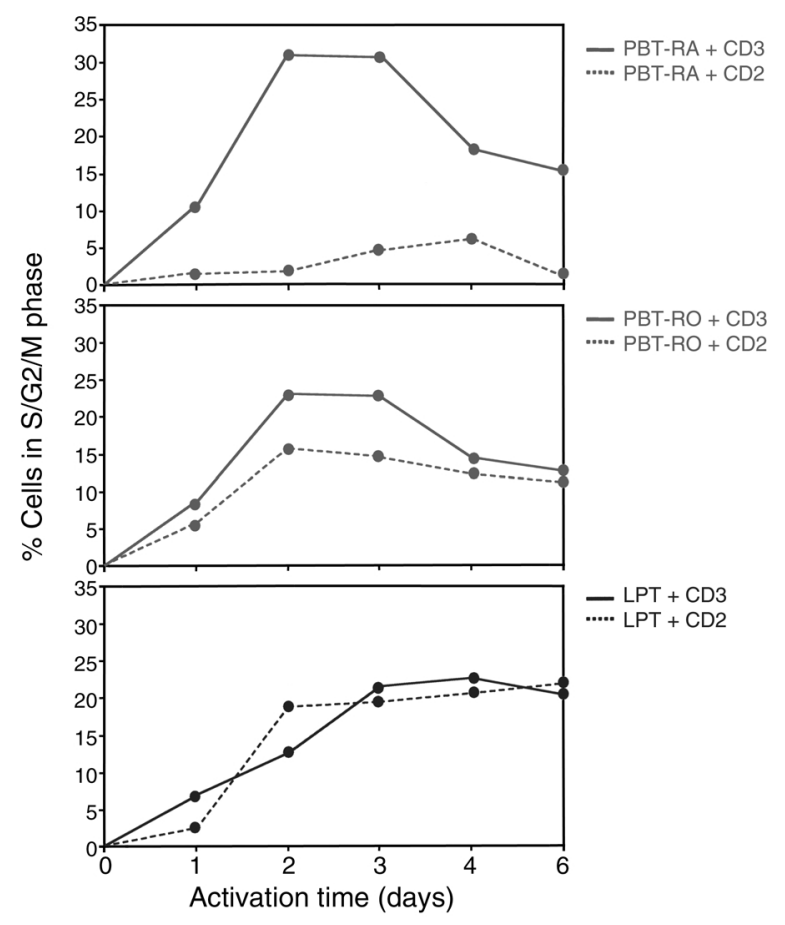

Figure 2

Distinct cell cycle profiles of CD45RA ${ }^{+}$PBTs, CD45RO ${ }^{+}$PBTs, and LPTs. The number of CD3-activated LPTs in the $S$ and G2/M phase peaks at 4- 6 days, in contrast to CD45RA ${ }^{+}$and CD45RO ${ }^{+}$PBTs, which peak at 2-3 days. CD2-activated LPTs in the $S$ and G2/M phase peak at 4-6 days, in contrast to CD45RA ${ }^{+}$PBTs, which mostly remain in the G0/G1 phase, and CD45RO+ PBTs, which peak at 3 days and then decline. Freshly isolated PBTs and LPTs were cultured with anti-CD3 or -CD2 mAb, and each phase of the cell cycle was assessed by measuring DNA content by PI staining followed by flow cytometry. The graphs are representative of eight different experiments.

this method only measures DNA synthesis during the $S$ phase and provides no information on the fraction of cells going through the other phases, including resting (G0/G1), mitotic (G2/M), dividing (M), and apoptotic cells (3). To determine whether PBTs and LPTs differ in regard to distribution in each cell cycle phase, and whether their different composition of naive $\left(\mathrm{CD} 45 \mathrm{RA}^{+}\right)$and memory $\left(\mathrm{CD} 45 \mathrm{RO}^{+}\right)$cells affects the results, we performed a complete analysis of their cycling profiles in response to $\mathrm{CD} 3$ and $\mathrm{CD} 2$ activation. Immediately after isolation, more than $98 \%$ of PBTs and LPTs were in G0/G1, regardless of naive or memory status. After a 3-day activation with $\mathrm{CD} 3 \mathrm{mAb}$, the percentage of CD45RA ${ }^{+}$PBTs in the G0/G1 phase dropped to $70 \% \pm 3.1 \%$, while those in the $\mathrm{S}$ and $\mathrm{G} 2 / \mathrm{M}$ phase increased to $30 \% \pm 3.5 \%$ (Figure 2). After the same period of time, $77 \% \pm 4.1 \%$ of the $\mathrm{CD}^{2} 5 \mathrm{RO}^{+} \mathrm{PBTs}$ were in the $\mathrm{G0} / \mathrm{G} 1$ and $23 \% \pm 2.9 \%$ were in the $\mathrm{S}$ and $\mathrm{G} 2 / \mathrm{M}$ phase. In contrast, $80 \% \pm 4.3 \%$ of LPTs remained resting in the G0/G1 phase and $20 \% \pm 2.4 \%$ cells advanced to the $\mathrm{S}$ and $\mathrm{G} 2 / \mathrm{M}$ phase (Figure 2). When activation was induced with anti-CD2 mAb, only $5 \% \pm 1.7 \%$ of $\mathrm{CD}_{45 \mathrm{RA}^{+}}$PBTs and $15 \% \pm 2 \%$ of the CD $45 \mathrm{RO}^{+} \mathrm{PBTs}$ cycled, whereas LPTs behaved like CD3-activated LPTs (Figure 2). Interestingly, the number of LPTs cycling in response to both $\mathrm{CD} 3$ and $\mathrm{CD} 2$ stimulation remained high at later time points (4-6 days), while the number of CD3-activated CD45RA ${ }^{+}$and $\mathrm{CD}^{2} 5 \mathrm{RO}^{+}$PBTs continued to drop (Figure 2).

Next, we performed stathmokinetic analysis to determine the time taken by PBTs and LPTs to traverse each cycle phase. This was accomplished using nocodazole as a metaphase inhibitor and BrdU incorporation to model and measure cell cycle kinetics $(27,38,39)$. The G0/G1, S, and G2/M phase traverse times of PBTs activated by $\mathrm{CD} 3$ signaling were substantially faster than when cells were activated through CD2 (Table 1). In LPTs, the times the cells spent in each phase were comparable in response to $\mathrm{CD} 3$ and $\mathrm{CD} 2$ activation, but longer than that of CD3-activated PBTs (Table 1). Calculation of potential doubling times $\left(T_{\text {pot }}\right)$ showed that it takes 1 day (24 hours) for CD3-activated PBTs to double, but 4 days (104 hours) days for CD2-activated PBTs. In contrast, it takes nearly 2 days for LPTs to double, regardless of CD3 (47 hours) or CD2 (39 hours) stimulation (Table 1).

Different levels of cell cycle promoters in PBTs and LPTS. Having established that PBTs and LPTs display important differences in cell cycle kinetics, we next investigated how levels of key regulatory molecules responsible for initiating and advancing each phase of the cell cycle varied in the two cell populations $(40,41)$. Western blot analysis showed that CDK4 and cyclin D3, the main regulators of the G1 phase, were upregulated only in CD3-activated PBTs, not in PBTs activated by CD2 or in LPTs activated by $\mathrm{CD} 3$ or $\mathrm{CD} 2 \mathrm{mAb}$ (Figure 3a). Similar results were obtained for cyclin D2 (data not shown). The analysis of $\mathrm{Rb}$, which is essential for the G1/S phase transition, showed that increase in phosphorylation was marked in CD3-activated, but small in CD2-activated, PBTs (Figure 3a). This regulatory profile was entirely different in LPTs, since engagement of either the CD2 or the $\mathrm{CD} 3$ pathway led to a comparable increase of $\mathrm{Rb}$

Table 1

Differential effect of CD3 and CD2 activation on PBT and LPT cell cycle kinetics

\begin{tabular}{|c|c|c|c|c|c|}
\hline & G0/G1 traverse time $\mathrm{A}^{\mathrm{A}}$ & $\mathrm{S}$ traverse time $\mathrm{A}^{\mathrm{A}}$ & $\mathrm{G} 2 / \mathrm{M}$ traverse time $\mathrm{A}^{\mathrm{A}}$ & Potential doubling time $\left(T_{p o t}\right)^{A}$ & Cells in mitosis $(\%)^{\mathrm{B}}$ \\
\hline PBT CD3 & $5.7 \pm 0.8$ & $14.2 \pm 1.5$ & $4.1 \pm 0.5$ & 24.0 & $1.28 \pm 0.14$ \\
\hline PBT CD2 & $35.1 \pm 2.1$ & $42.6 \pm 5.2$ & $26.1 \pm 1.0$ & 103.8 & $0.02 \pm 0.02$ \\
\hline LPT CD3 & $7.9 \pm 1.1$ & $31.2 \pm 2.9$ & $8.2 \pm 0.9$ & 47.3 & $0.49 \pm 0.03$ \\
\hline LPT CD2 & $7.6 \pm 0.9$ & $25.4 \pm 3.1$ & $6.4 \pm 2.8$ & 39.4 & $0.64 \pm 0.05$ \\
\hline
\end{tabular}

AValues represent time in hours. ${ }^{B}$ Percentage of phospho-histone $\mathrm{H} 3$-positive cells at 72 hours. 

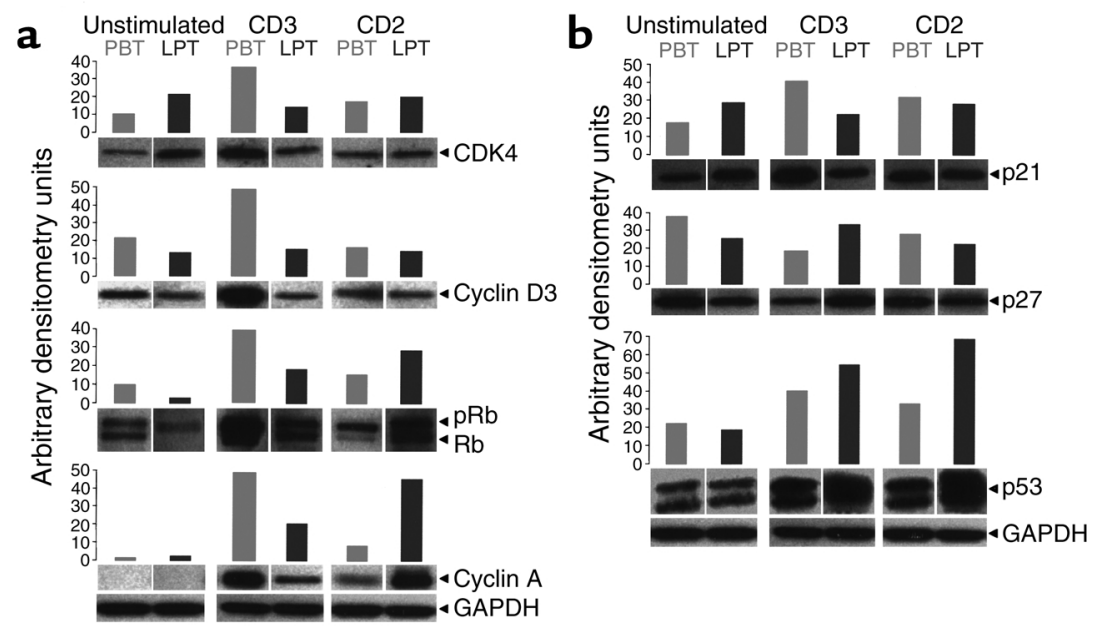

\section{Figure 3}

(a) Different levels of cell cycle promoters in PBTs and LPTs. Immunoblot analysis shows that upregulation of CDK4 and cyclin D3 is only detected in CD3-activated PBTs, but not in PBTs or LPTs activated through the CD2 and CD3 pathways. Rb phosphorylation ( $p R b$ ) was minimal in CD2-activated PBTs but markedly increased after CD3 activation, whereas, in LPTs, engagement of either the CD2 or CD3 pathway led to strong Rb phosphorylation. Strong upregulation of cyclin A in PBTs was induced by CD3 activation, whereas CD2 activation was required for an equally strong upregulation in LPTs. (b) Different levels of cell cycle inhibitors in PBTs and LPTs. The level of p21 varies little in unstimulated and stimulated PBTs and LPTs, except for a moderate increase in CD3-activated PBTs. Levels of the inhibitor p27 are downregulated in CD3-stimulated PBTs but not CD3-stimulated LPTs. Activation through the CD2 pathway induces a striking upregulation of p53 in LPTs but only a moderate increase in PBTs, whereas CD3 stimulation induces a lower and comparable p53 upregulation in PBTs and LPTs. Freshly isolated PBTs and LPTs were cultured in the absence and presence of CD3 or CD2 mAb for 3 days, after which expression of cell cycle inhibitors was assessed by Western blotting. Each bar represents the densitometry units of individual protein bands normalized to their own GAPDH. Each panel is representative of five to seven different experiments.

phosphorylation. The levels of p107 and p130, the other two members of the $\mathrm{Rb}$ protein family, did not significantly change in either cell type, regardless of the stimulation pathway used (data not shown).

We also analyzed cyclins A and B1, responsible for leading the cells to mitosis after they passed the restriction point at the G1/S interphase. Distinct activation pathways appeared to be responsible for progression of PBTs and LPTs through the S phase. In fact, strong upregulation of cyclin A in PBTs was only induced by $\mathrm{CD} 3$ activation, whereas $\mathrm{CD} 2$ activation was required for an equally strong upregulation of cyclin A in LPTs (Figure 3a). Cyclin B1 was examined by flow cytometry in conjunction with PI staining to exactly localize its increase within the cell cycle. The expression of cyclin B1 in the G2/M phase of CD3activated PBTs and CD2-activated LPTs paralleled the expression of cyclin A during the previous phase of the cell cycle (Figure 3). Furthermore, cells positive for phosphorylated histone $\mathrm{H} 3$, a mitosis marker exclusively detectable during unfolding of DNA in mitosis (42), were present in CD3-activated but essentially absent in CD2-activated PBTs, while equal numbers were found in CD2- and CD3-activated LPTs (Figure 4 and Table 1). The variations observed in protein lev- els of cell cycle promoters were confirmed at the mRNA level by ribonuclease protection assay (data not shown).

Different levels of cell cycle inbibitors in PBTs and LPTs. To complement the study of cell cycle promoters, we next determined expression levels of the key cell cycle inhibitors p21, p27, and p53. p21 levels did not significantly differ in unstimulated and stimulated PBTs and LPTs, except for an increase in CD3-activated PBTs, a finding in agreement with the role that $\mathrm{p} 21$ also plays in cell proliferation (Figure 3b) (43). Levels of the inhibitor p27 were downregulated in CD3-stimulated PBTs but not CD3-stimulated LPTs. In contrast with these inhibitors, major differences in the levels of p53 were observed that further confirmed the existence of distinct cell cycle regulatory patterns between PBTs and LPTs. Activation through the CD2 pathway induced a striking upregulation of p53 in LPTs but only a modest increase in PBTs, whereas CD3 stimulation induced a lower and similar upregulation in PBTs and LPTs (Figure 3b). Differences observed in protein levels of cell cycle promoters were confirmed at the mRNA level by ribonuclease protection assay (data not shown).

Differential clonal expansion and telomerase activity of PBTs and LPTs. We next measured clonal expansion to establish the actual capacity of PBTs and LPTs to divide in response to receptor activation. Using the CFDA lipophilic dye, we determined the number of cell divisions by measuring the dilution of the dye in each successive daughter population. Because of the distinct cell cycle kinetics observed in $\mathrm{CD}^{4} 5 \mathrm{RA}^{+}$PBTs, $\mathrm{CD}_{45 \mathrm{RO}^{+}} \mathrm{PBTs}$, and LPTs, clonal expansion was measured in each of these populations. After 4-day stimulation with anti-CD3 mAb, three cell divisions comprising $70-90 \%$ of the original population were noted in

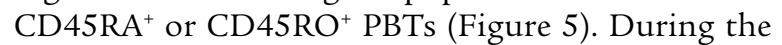
same period of time, only $30 \%$ of equally stimulated LPTs divided, even though the number of cell divisions was the same. When clonal expansion in response to CD2 was investigated, an opposite pattern was observed. At least three divisions comprising more than $70 \%$ of the cells were induced in LPTs, whereas only $5-10 \%$ of $\mathrm{CD}^{2} 5 \mathrm{RA}^{+}$or $\mathrm{CD} 45 \mathrm{RO}^{+} \mathrm{PBTs}$ divided in response to $\mathrm{CD} 2$ stimulation (Figure 5).

A step indispensable for cell division to occur is preservation of chromosome telomere length, a process 

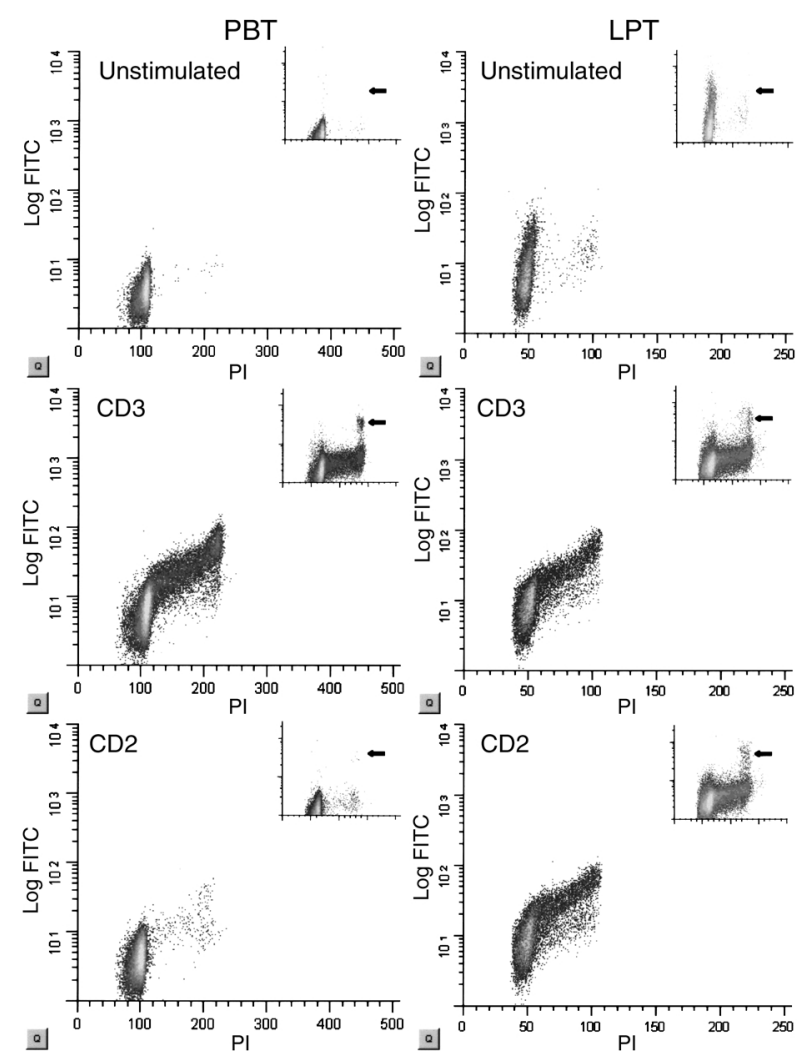

Figure 4

Different levels of cyclin B1 and phospho-histone $\mathrm{H} 3$ in PBTs and LPTs. Flow cytometric analysis shows increase of cyclin B1 expression in the G2/M phase of anti-CD3-activated PBTs and anti-CD3and anti-CD2-activated LPTs. The right upper inserts represent the phospho-histone $\mathrm{H} 3$-positive cells ( $y$ axis), and the arrows indicate the mitotic cell population. Freshly isolated PBTs and LPTs were cultured in the absence and presence of CD3 or CD2 mAb for 3 days, after which cyclin $\mathrm{B} 1$ and $\mathrm{H} 3$ expression and DNA content were examined by flow cytometry. The figure is representative of seven different experiments.

strictly dependent on the activity of the enzyme telomerase (21). We therefore measured this enzyme activity in CD3- and CD2-stimulated PBTs and LPTs. Telomerase activity was essentially undetectable in unstimulated PBTs and LPTs and in CD2-stimulated PBTs but increased substantially in CD3-activated PBTs (Figure 6 , a and b). In LPTs, telomerase activity was induced by both $\mathrm{CD} 2$ and $\mathrm{CD} 3$ activation, reaching only half of the level seen in CD3-activated PBTs.

Mitochondrial membrane potential in PBTs and LPTs. The marked differences observed in the capacity of PBTs and LPTs to cycle and divide in response to CD3 and CD2 receptor engagement suggest that the capacity to generate the energy required for these crucial processes may vary depending on the cell type or pathway of stimulation. To investigate this possibility we used the redistribution of the dye rhodamine123, a lipophilic cation that accumulates in the mitochondrial membrane (31). When we used the same cells used in the 4-day stimulation clonal expansion protocol, CD3-activated PBTs showed a clear increase in mitochondrial polarization potential compared with unstimulated cells (Figure 7). Intriguingly, a comparable increase was observed in both CD3- and CD2-activated LPTs, despite their marked differences in clonal expansion. In sharp contrast, CD2-activated PBTs showed no increase in mitochondrial polarization potential (Figure 7).

Inhibitory role of $p 53$ in cell cycle progression and apoptosis of LPTs. The clear differences in cycle kinetics between PBTs and LPTs, combined with the striking activationinduced elevation of p53 in LPTs, suggested that p53 was responsible for the slow cycle progression of LPTs and their known increased susceptibility to apoptosis (16). To investigate this possibility, blockade of $\mathrm{p} 53$ was carried out using specific antisense oligonucleotides, and its impact on cell cycle progression as well as apoptosis was assessed.

Under the experimental condition previously used, treatment of PBTs and LPTs with p53 antisense oligonucleotides inhibited $\mathrm{p} 53$ expression in both cell types regardless of $\mathrm{CD} 3$ or $\mathrm{CD} 2$ activation, but the remaining phosphorylated $\mathrm{p} 53$ levels were clearly higher in LPTs than in PBTs (Figure 8). Scrambled control oligonucleotides had no effect on $\mathrm{p} 53$ expression. Since $\mathrm{p} 53$ and $\mathrm{Rb}$ are both critically involved in controlling the restriction point at the G1/S interphase (44), we also

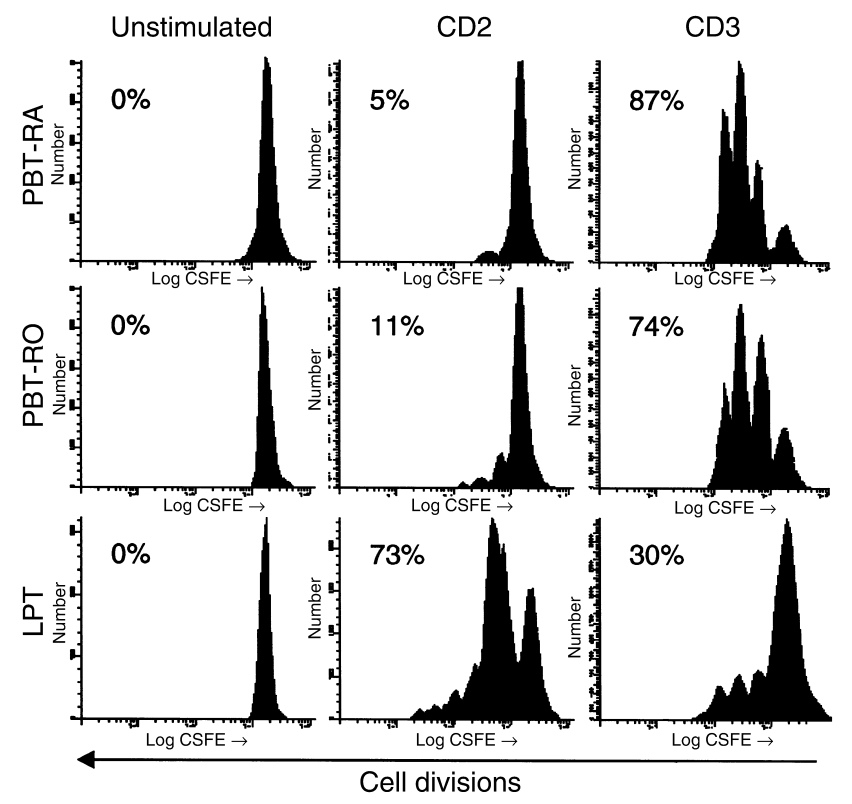

Figure 5

Clonal expansion of CD3- and CD2-activated CD45RA ${ }^{+}$PBTs, CD45RO+ PBTs, and LPTs. After 4 days' stimulation, CD3 activation induces a greater clonal expansion in both CD45RA ${ }^{+}$and CD45RO ${ }^{+}$ PBTs than in LPTs, whereas in CD2-activated cells clonal expansion is strikingly greater in LPTs than in both CD45RA ${ }^{+}$and CD45RO ${ }^{+}$ PBTs. The first peak to the right represents the undivided cell population. The numbers indicate the percentage of divided cells distributed in the subsequent peaks. Freshly isolated CD45RA ${ }^{+}$and $\mathrm{CD}_{45 \mathrm{RO}^{+}}$PBTs and LPTs were incubated with $5 \mu \mathrm{M} \mathrm{CFDA}$ and cultured in the absence and presence of CD3 or CD2 mAb for 4 days, and cell divisions were determined by flow cytometry. The figure is representative of six to nine different experiments. 


\section{a}

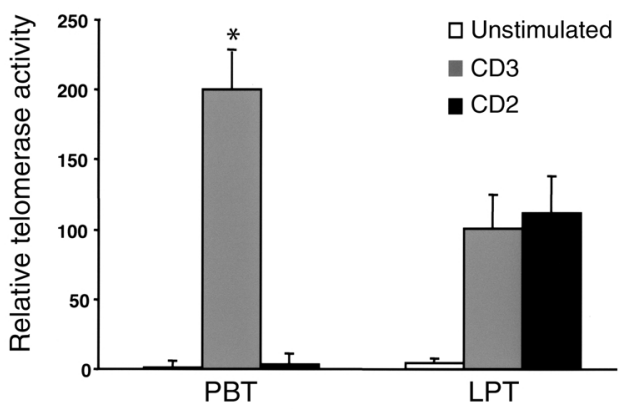

b

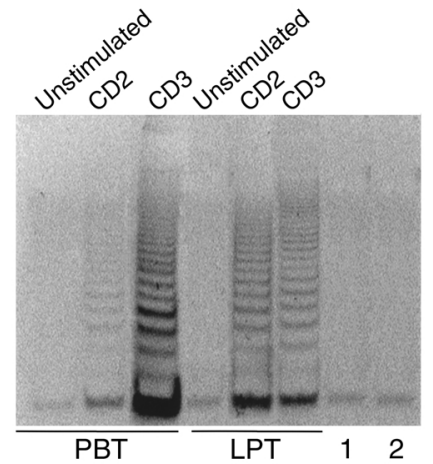

\section{Figure 6}

Telomerase activity of CD3- and CD2-activated PBTs and LPTs. (a) In PBTs, telomerase activity is induced only by CD3 activation, whereas both anti-CD3 and anti-CD2 activation induces enzymatic activity in LPTs. The level of activity is significantly greater in antiCD3-stimulated PBTs than in both anti-CD3- and anti-CD2-activated LPTs $\left({ }^{*} P<0.05\right)$. (b) Display of the telomeric-mediated sixnucleotide ladder. The intensity of expression closely correlates with the level of enzymatic activity seen in a. Freshly isolated PBTs and LPTs were cultured in the absence and presence of CD3 or CD2 mAb for 3 days, after which cells were lysed, amplified, and analyzed either by telomerase activity or Southern blot using a nondenaturing bis-acrylamide gel. 1, lysis buffer control; 2, heat-treated control (anti-CD3-activated PBTs). Each bar represents mean \pm SEM of five to seven experiments.

assessed the effect of $\mathrm{p} 53$ antisense oligonucleotides on $\mathrm{Rb}$ expression. In agreement with the role of $\mathrm{p} 53$ in cell cycle regulation, a substantial increase in $\mathrm{Rb}$ expression was noted in PBTs and LPTs, corresponding to the p53 blockade-induced downregulation (Figure 8).

To define the functional significance of the different levels of $\mathrm{p} 53$ between activated PBTs and LPTs and confirm that p53 was actually responsible for the slow cycle progression of LPTs, we used BrdU incorporation to measure the relative movement through the $S$ phase of cells treated with p53 antisense oligonucleotides. Regardless of the pathway of activation, blockade of p53 by antisense oligonucleotides was able to overcome the slow cycling of LPTs and enhanced their relative movement to the same high level as that of CD3-activated PBTs (Figure 9, a and b). Blockade of p53 in LPTs resulted in a $65 \%$ and $60 \%$ shortening of DNA synthesis time of CD3- and CD2-activated LPTs, respectively, while it decreased DNA synthesis time by $34 \%$ in CD3activated, and $45 \%$ in CD2-activated, PBTs (Table 2).

Because of the role of p53 in apoptosis $(44,45)$, we also investigated the effects of its blockade on apop- tosis of CD3- and CD2-activated PBTs and LPTs. As expected, apoptosis was substantially greater in unstimulated LPTs than in unstimulated PBTs (Table 2) (16). Activation through the $\mathrm{CD} 3$ or $\mathrm{CD} 2$ pathway failed to significantly alter the level of PBT cell death, and no additional effect was observed with p53 antisense oligonucleotide treatment. In sharp contrast, activation of either pathway enhanced LPT apoptosis, and this response was markedly inhibited by p53 blockade (Table 2).

\section{Discussion}

LPTs represent a population of immune cells generated in gut-associated lymphoid tissue that traffic through the systemic circulation prior to homing to the intestinal mucosa (46). Once localized, LPTs acquire highly specialized functions aimed at maintaining immune homeostasis by establishing a state of tolerance to dietary and bacterial antigens $(47,48)$. Local homeostasis requires a tight regulation of LPT responses, including proliferation, clonal expansion, cytokine production, and balance between cell death and survival. These responses differ substantially from those of PBTs, reflecting the fundamental changes PBTs undergo during the process of differentiation from a naive into a memory cell (10). Antigen stimulation triggers $\mathrm{T}$ cell cycle progression and clonal expansion, both of which are essential to mount an effective immune response. We focused our study on a detailed investigation of how LPTs differ from PBTs in regard to these two critical parameters.

We initially investigated the cell cycle profiles of PBTs and LPTs over an extended period of time to gain

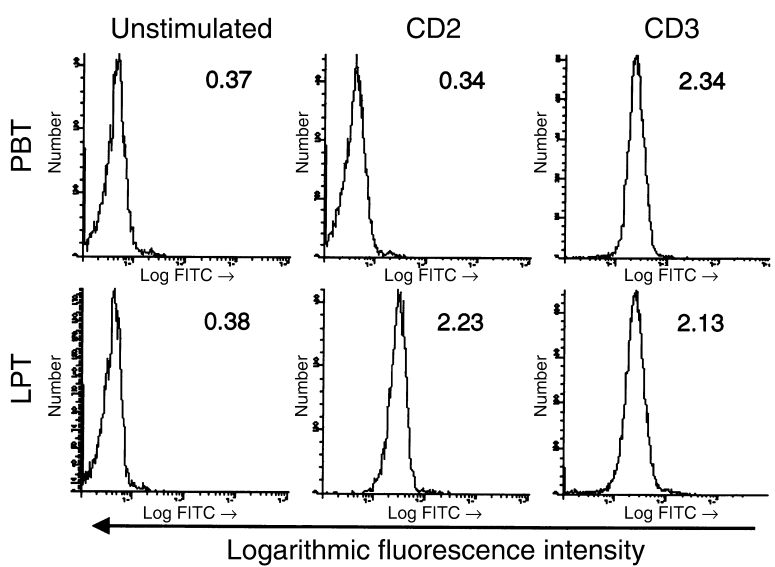

\section{Figure 7}

Mitochondrial membrane potential in PBTs and LPTs. After 4 days' stimulation through the CD2 or CD3 pathway, LPTs display a clear increase in the mitochondrial membrane potential, comparable to that observed in CD3-activated PBTs. CD2-activated PBTs show no significant increase. Freshly isolated PBTs and LPTs were cultured in the absence and presence of $C D 3$ or $C D 2 \mathrm{mAb}$ for 4 days, after which mitochondrial membrane potential was assessed by rhodamine 123 staining followed by flow cytometry. Each graph is representative of five to eight experiments. Numbers indicate mean fluorescence intensity. 


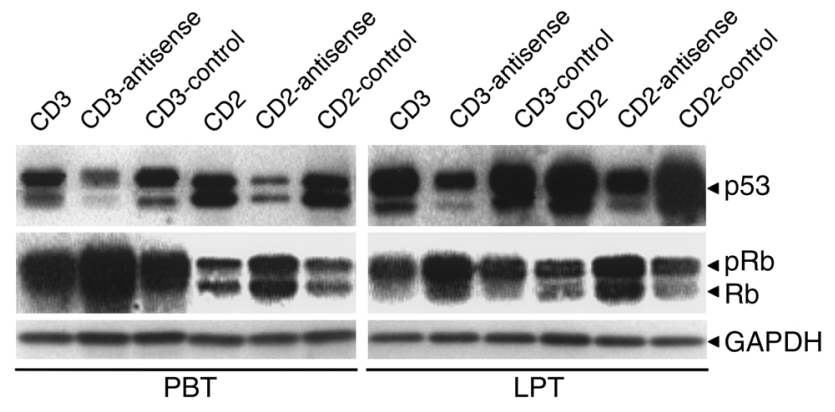

Figure 8

Effect of antisense treatment on p53 and Rb levels in PBTs and LPTs. Treatment with $p 53$ antisense oligonucleotides decreases $p 53$ expression but substantially increases Rb phosphorylation in CD3- or CD2activated PBTs and LPTs. Freshly isolated PBTs and LPTs were cultured for 3 days in the presence or absence of p53 antisense oligonucleotides, scrambled controls, anti-CD3 mAb, or anti-CD2 mAb, after which $\mathrm{p} 53$ and $\mathrm{Rb}$ protein levels were assessed by Western blotting. Each panel is representative of five different experiments.

an overview of possible differences between them, including the effect of their state of differentiation. In response to $\mathrm{CD} 3$ stimulation, both $\mathrm{CD}_{45 \mathrm{RA}^{+}}$and $\mathrm{CD}_{45 \mathrm{RO}^{+}}$PBTs generated the highest percentage of cycling cells at $2-3$ days, as shown by peaking in the $S$ and $\mathrm{G} 2 / \mathrm{M}$ phase. In contrast, LPTs displayed a delayed response, peaking in the $S$ and $\mathrm{G} 2 / \mathrm{M}$ phase at day 4-6, a time when most PBTs had already returned to G0/G1. The delayed but equally robust $\mathrm{S}$ phase of LPTs may explain why proliferation of CD3-activated LPTs is less than that of PBTs if measured only by a short-term tritiated thymidine uptake $(10,13,14,37)$. At 4-6 days, the number of LPTs in the S phase was comparable to that of PBTs at 2-3 days, suggesting a delayed capacity of LPTs to respond to CD3 stimulation. Differences between PBTs and LPTs were further emphasized when cells were stimulated through the CD2 pathway, which is particularly effective in activating LPTs $(13,14)$. Cycling was minimal in CD2-activated $\mathrm{CD}_{45 \mathrm{RA}^{+}} \mathrm{PBTs}$, and $\mathrm{CD} 45 \mathrm{RO}{ }^{+}$PBTs peaked at 2 days before declining, while at 4-6 days the number of LPTs in the $\mathrm{S}$ and $\mathrm{G} 2 / \mathrm{M}$ phase was as high and sustained as that induced by CD3 stimulation. These results demonstrate that LPTs display an intrinsically delayed response that is independent of activating signals or state of differentiation.

The above results show that the number of PBTs and LPTs in the various phases of the cell cycle clearly differs depending on the activating signal, but they provide no information on how quickly each cell moves through the individual phases of the cycle. Knowing the time spent in each phase is critical because it translates how quickly a $\mathrm{T}$ cell reaches mitosis and divides (49). Activation of PBTs with anti-CD3 mAb led to a short S phase, resulting in a 24 -hour potential doubling time, while LPTs spent more than twice as long in the $S$ phase, with a potential doubling time of nearly 48 hours. When activation was through the CD2 pathway, the $S$ phase of PBTs lasted 2 days and the potential doubling time was greater than 4 days, while the $\mathrm{S}$ phase of LPTs was shorter than that of CD2-activated PBTs and CD3-activated LPTs, with a doubling time of less than 2 days. These differences in the potential doubling time of PBTs and LPTs were consistent with the corresponding differences in the G2/M entry times measured by nocodazole blockade. The short $S$ phase and G2/M entry times of CD3-activated PBTs, combined with a short doubling time, suggest that these cells both cycle and divide rapidly. The same responses are delayed in both CD3- and CD2-activated LPTs, indicating a slower cell cycle progression of LPTs. These differences suggest that, during an immune response, more time is required to obtain an equal number of cycling LPTs than PBTs.

To understand the molecular mechanisms underlying the unique behavior of LPTs during the cell cycle, we measured expression level of key promoters responsible for progression of distinct phases of the cycle (CDK4, cyclins D2 and D3, Rb, cyclin A, and cyclin B1) (17), as well as relevant inhibitors (p21, p27, and p53) $(18,19)$. The delayed cycling of LPTs immediately after
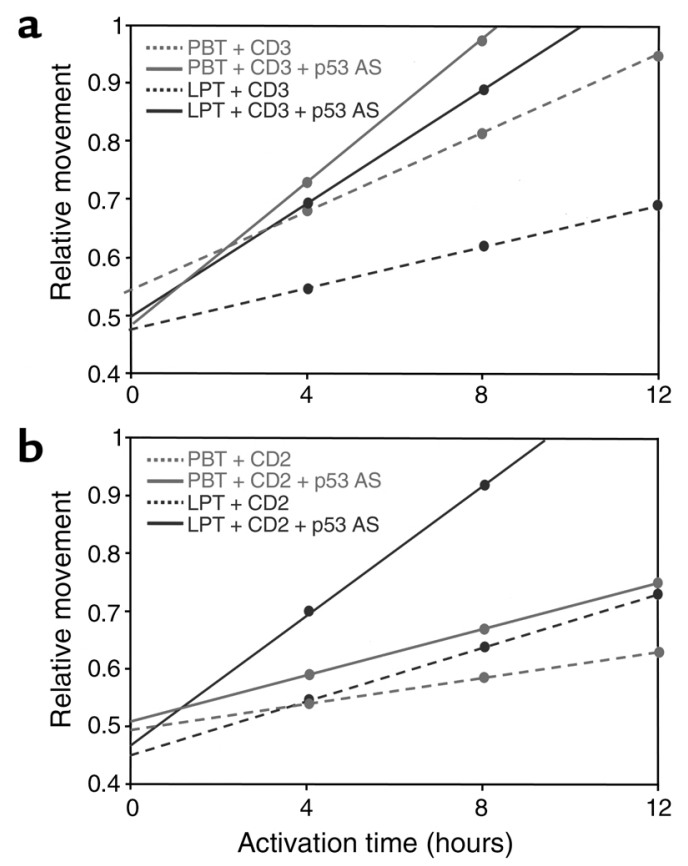

\section{Figure 9}

Effect of p53 antisense treatment on relative movement of PBTs and LPTs. (a) Treatment with p53 antisense (AS) oligonucleotides increases the relative movement of CD3-activated PBTs by $34 \%$ and of CD3-activated LPTs by $65 \%$. (b) Treatment increases the relative movement of CD2-activated PBTs by $45 \%$ and of CD2-activated LPTs by $60 \%$. Freshly isolated PBTs and LPTs were cultured in the presence or absence of p53 antisense oligonucleotide, scrambled controls, anti-CD3 mAb, or anti-CD2 mAb and, 3 days later, incubated with $20 \mu \mathrm{M} \mathrm{BrdU}$ and restimulated with the same mAb. Relative movement was calculated as described in Methods. Each line represents the mean \pm SEM of five experiments. The relative movement after antisense treatment was significantly higher in both anti-CD3- and anti-CD2-activated PBTs and LPTs than in their respective nontransfected and scrambled controls $(P<0.05)$. 
Table 2

Effect of p53 blockade on PBT and LPT cell cycle kinetics

\begin{tabular}{lccccc}
\hline & p53 antisense treatment & DNA synthesis time & Percent change & Potential doubling time $\left(T_{\text {pot }}\right)^{\mathrm{A}}$ & ${\text { Apoptotic cells }(\%)^{\mathrm{B}}}$ \\
PBT CD3 & - & $13.2 \pm 1.2$ & & 25 & $3.1 \pm 0.8$ \\
& + & $8.7 \pm 0.7$ & +34 & 16 & $1.9 \pm 0.2$ \\
PBT CD2 & - & $44.3 \pm 3.9$ & & 105 & $3.5 \pm 0.7$ \\
& + & $24.5 \pm 2.9$ & +45 & 56 & $1.4 \pm 0.5$ \\
LPT CD3 & - & $29.1 \pm 3.5$ & & 44 & $27.0 \pm 2.1$ \\
& + & $10.1 \pm 1.4$ & +65 & 41 & $15.1 \pm 1.8$ \\
LPT CD2 & - & $23.0 \pm 2.0$ & +60 & 18 & $24.0 \pm 2.6$ \\
& + & $9.1 \pm 1.1$ & & $4.7 \pm 1.6$
\end{tabular}

AValues represent time in hours. ${ }^{B}$ Percentage PI-positive cells at 72 hours.

stimulation with $\mathrm{CD} 2$ or $\mathrm{CD} 3 \mathrm{mAb}$ could be related to the lack of upregulation of CDK4 and cyclin D3. Nevertheless, when LPTs go through the G1/S transition and pass the restriction point, the relative increase in $\mathrm{Rb}$ phosphorylation induced by CD2 was at least as strong as that induced by CD3. Phosphorylation of the pocket protein $\mathrm{Rb}$ releases essential cell cycle progression factors such as E2F oncogene products (50). In response to $\mathrm{CD} 2$ activation, $\mathrm{PBT}$ failed to phosphorylate $\mathrm{Rb}$ and initiate cycle entry, whereas LPTs readily phosphorylated $\mathrm{Rb}$, further stressing the importance of the CD2 pathway in mucosal $\mathrm{T}$ cell reactivity. This was further emphasized by the striking upregulation of cyclins A and B1 by activation of the CD2 pathway in LPTs, comparable to the upregulation of the same mediators in CD3-activated PBTs.

Taking into consideration the results so far, it can be concluded that CD2 stimulation is able to put in motion a series of events leading to an effective but controlled cycling of LPTs. Antigen encounter causes T cells to clonally expand, a process requiring repeated cell divisions $(51,52)$. This process clearly differs between LPTs and PBTs in view of our findings of distinct cell cycle kinetics in the two populations. Repeated cell divisions require activation of the enzyme telomerase to preserve telomere length, which controls the replicative potential and lifespan of T cells $(20,21)$. CD2 activation and CD3 activation were equally effective in inducing telomerase activity in LPTs, though less effective in inducing it in PBTs. Yet LPT clonal expansion induced by CD2 was as strong as that of CD3-activated $\mathrm{CD}^{4} \mathrm{R} \mathrm{R}^{+}$or $\mathrm{CD}_{45 \mathrm{RO}^{+}}$PBTs, showing that LPTs' slow replicative capacity delays but does not prevent active clonal expansion. Thus, LPTs respond in a slower, time-controlled, but highly effective way that is seemingly conditioned by the mucosal microenvironment and not simply by their memory status. This unique response pattern may lessen the dangers of exceedingly swift or abrupt immune response in the mucosa and minimize the risks of inducing inflammation.

The process of cell division necessary for clonal expansion requires energy (53). In view of the different number of cell divisions induced in PBTs and LPTs by CD3 and CD2 activation, we measured mitochondrial membrane potential as an indication of their capacity to generate energy in response to these two stimuli
(31). In agreement with the finding that more than 98\% of freshly isolated PBTs and LPTs are in G0/G1 phase, each cell type displayed baseline membrane potential levels when cultured alone, confirming that, despite their naive and memory cell status, both stay quiescent in the absence of exogenous stimuli. The high number of cell divisions observed in CD2-activated LPTs and CD3-activated PBTs was associated with an identical increase in mitochondrial membrane potential, showing that, during clonal expansion, as much energy is generated by CD2-activated LPTs than by CD3-activated PBTs. In agreement with the weak capacity of CD2 to propel the cell cycle of PBTs, no increase in mitochondrial membrane potential resulted from stimulation of PBTs with CD2 mAb. Surprisingly, despite inducing a lower number of cycling and daughter cells, CD3 activation of LPTs generated energy levels as high as those of CD3-activated PBTs or CD2-activated LPTs, suggesting a utilization pattern other than clonal expansion.

As judged by the observed cell cycle parameters, it is evident that LPTs are restricted in their ability to cycle. However, as measured by mitochondrial membrane potential, LPTs are as vigorously activated as PBTs, suggesting that a powerful endogenous inhibitor regulates the mucosal $T$ cell cycle. While activation caused minor variations in the level of p 21 and p 27 in PBTs and LPTs, a striking upregulation of p53 was observed in LPTs upon stimulation with CD2 mAb. This elevation may compensate for the strong CD2-mediated induction of cell cycle promoters and ensure a controlled cycling of LPTs. These results make p53 an endogenous regulator that, by limiting the proliferation of LPTs, may act as a break against excessive reactivity toward bacterial and food antigens. In fact, blockade of endogenous p53 by antisense oligonucleotides resulted in greater acceleration of the cell cycle in LPTs than in PBTs, speeding the S phase transit time of LPTs to that of CD3-activated PBTs. In addition to the dual role of p53 as a cell cycle inhibitor and apoptosis promoter (22), its blockade also diminished activation-induced LPT apoptosis, highlighting a role in controlling LPT function. p53 is known to induce the proapoptotic Bax protein (23), and the high level of p53 in LPTs may explain why they contain a large quantity of this protein (54). Because p53 is a 
physiological regulator of the cell cycle, its abundance in normal LPTs suggests a central role in mucosal immunity and immune tolerance. Upholding this concept is the observation that p53 is downregulated in LPTs from patients with Crohn disease, a condition where tolerance is lost, and that this downregulation is associated with faster cell cycling and increased number of cell divisions (A. Sturm, unpublished observations). This supports the key role of cell cycle regulation in immunity, tolerance, and autoimmunity (3).

In conclusion, in contrast to PBTs, activation of LPTs leads to an inherently slower progression through the cell cycle, resulting in delayed replication that is not explained by their memory status. In particular, CD2 stimulation of LPTs induces $\mathrm{Rb}$ phosphorylation together with remarkably high levels of the inhibitor p53, whose blockade leads to a dramatic acceleration of LPT cell cycling. Since LPTs must limit their reactivity to maintain local immune homeostasis, the p53dependent slow cycling of LPTs likely reflects the need for a strict control in response to the gut's heavy antigenic load. In this regard, p53 behaves similarly to the lung Krüpple-like transcription factor and Tob antiproliferative protein, which also contribute to maintenance of $\mathrm{T}$ cell quiescence through active and highly regulated processes $(55,56)$. The results of this study show that $\mathrm{p} 53$ plays a previously unrecognized role as a negative regulator of mucosal immunity by restraining a uniquely tuned but effective mucosal $\mathrm{T}$ cell replication, which may prevent excessive reactivity and contribute to maintaining tolerance.

\section{Acknowledgments}

This work was supported by grants from the NIH (DK30399 and DK-50984 to C. Fiocchi), the National Cancer Institute (CA-73413 and CA-43703 to J.W. Jacobberger), and the Deutsche Forschungsgemeinschaft (DFG247/2-1 to A. Sturm). We thank Gail West, R. Michael Sramkoski, and Megan Gottlieb for technical assistance. We also thank the Departments of Surgery and Pathology of the University Hospitals of Cleveland, and the Colorectal Surgery Department of the Cleveland Clinic Foundation. Some tissue samples were provided by the Cooperative Human Tissue Network, which is funded by the National Cancer Institute.

1. Stillman, B. 1996. Cell cycle control of DNA replication. Science. 274:1659-1664.

2. Elledge, S.J. 1996. Cell cycle checkpoints: preventing an identity crisis. Science. 274:1664-1672.

3. Balomenos, D., and Martinez, A.C. 2000. Cell-cycle regulation in immunity, tolerance and autoimmunity. Immunol. Today. 21:551-555.

4. Lenardo, M., et al. 1999. Mature T lymphocyte apoptosis: immune regulation in a dynamic and unpredictable antigenic environment. Annu. Rev. Immunol. 17:221-253.

5. Klein, J.R. 1995. Advances in intestinal T-cell development and function. Immunol. Today. 16:322-324.

6. Mowat, A.M., and Viney, J.L. 1997. The anatomical basis of intestinal immunity. Immunol. Rev. 156:145-166.

7. Duchmann, R., Schmitt, E., Knolle, P., Meyer zum Buschenfelde, K.H., and Neurath, M. 1996. Tolerance towards resident intestinal flora in mice is abrogated in experimental colitis and restored by treatment with interleukin-10 or antibodies to interleukin-12. Eur. J. Immunol. 26:934-938.
8. Duchmann, R., Neurath, M.F., and Meyer zum Buschenfelde, K.H. 1997. Responses to self and non-self intestinal microflora in health and inflammatory bowel disease. Res. Immunol. 148:589-594.

9. Zeitz, M., Schieferdecker, H.L., James, S.P., and Riecken, E.O. 1990. Special functional features of T-lymphocyte subpopulations in the effector compartment of the intestinal mucosa and their relation to mucosal transformation. Digestion. 46:280-289.

10. Schieferdecker, H.L., Ullrich, R., Hirseland, H., and Zeitz, M. 1992. T cell differentiation antigens on lymphocytes in the human intestinal lamina propria. J Immunol. 149:2816-2822.

11. Qiao, L., Schurmann, G., Betzler, M., and Meuer, S.C. 1991. Functional properties of human lamina propria T lymphocytes assessed with mitogenic monoclonal antibodies. Immunol. Res. 10:218-225.

12. Hua, X., and Thompson, C.G. 2001. Quiescent T cells: actively maintaining inactivity. Nat. Immunol. 2:1097-1098.

13. Qiao, L., Schurmann, G., Betzler, M., and Meuer, S.C. 1991. Activation and signaling status of human lamina propria T lymphocytes. Gastroenterology. 101:1529-1536.

14. Targan, S.R., Deem, R.L., Liu, M., Wang, S., and Nel, A. 1995. Definition of a lamina propria $\mathrm{T}$ cell responsive state. Enhanced cytokine responsiveness of T cells stimulated through the CD2 pathway. J. Immunol. 154:664-675.

15. King, K.L., and Cidlowski, J.A. 1995. Cell cycle and apoptosis: common pathways to life and death. J. Cell. Biochem. 58:175-180.

16. Boirivant, M., et al. 1996. Stimulated human lamina propria T cells manifest enhanced Fas-mediated apoptosis. J. Clin. Invest. 98:2616-2622.

17. Sherr, C.J. 1994. G1 phase progression: cycling on cue. Cell. 79:551-555.

18. Sherr, C.J., and Roberts, J.M. 1995. Inhibitors of mammalian G1 cyclindependent kinases. Genes Dev. 9:1149-1163.

19. Sherr, C.J., and Roberts, J.M. 1999. CDK inhibitors: positive and negative regulators of G1-phase progression. Genes Dev. 13:1501-1512.

20. Hodes, R.J. 1999. Telomere length, aging, and somatic cell turnover. J. Exp. Med. 190:153-156.

21. Buys, C.H. 2000. Telomeres, telomerase, and cancer. N. Engl. J. Med. 342:1282-1283.

22. Amundson, S.A., Myers, T.G., and Fornace, A.J., Jr. 1998. Roles for p53 in growth arrest and apoptosis: putting on the brakes after genotoxic stress. Oncogene. 17:3287-3299.

23. Green, D.R., and Schuler, M. 2000. T cell development: some cells get all the breaks. Nat. Immunol. 1:15-17.

24. West, G.A., Matsuura, T., Levine, A.D., Klein, J.S., and Fiocchi, C. 1996. Interleukin 4 in inflammatory bowel disease and mucosal immune reactivity. Gastroenterology. 110:1683-1695.

25. Jacobberger, J.W., Sramkoski, R.M., Wormsley, S.B., and Bolton, W.E. 1999. Estimation of kinetic cell-cycle-related gene expression in G1 and G2 phases from immunofluorescence flow cytometry data. Cytometry. 35:284-289.

26. Zhang, D., and Jacobberger, J.W. 1996. TGF-beta 1 perturbation of the fibroblast cell cycle during exponential growth: switching between negative and positive regulation. Cell Prolif. 29:289-307.

27. Begg, A.C., McNally, N.J., Shrieve, D.C., and Karcher, H. 1985. A method to measure the duration of DNA synthesis and the potential doubling time from a single sample. Cytometry. 6:620-626.

28. White, R.A., Meistrich, M.L., Pollack, A., and Terry, N.H. 2000. Simultaneous estimation of $\mathrm{T}(\mathrm{G} 2+\mathrm{M}), \mathrm{T}(\mathrm{S})$, and $\mathrm{T}(\mathrm{pot})$ using single sample dynamic tumor data from bivariate DNA-thymidine analogue cytometry. Cytometry. 41:1-8.

29. Toescu, E.C., and Verkhratsky, A. 2000. Assessment of mitochondrial polarization status in living cells based on analysis of the spatial heterogeneity of rhodamine 123 fluorescence staining. Pflugers Arch. 440:941-947.

30. Pham, N.A., Robinson, B.H., and Hedley, D.W. 2000. Simultaneous detection of mitochondrial respiratory chain activity and reactive oxygen in digitonin-permeabilized cells using flow cytometry. Cytometry. 41:245-251.

31. Scaduto, R.C., Jr., and Grotyohann, L.W. 1999. Measurement of mitochondrial membrane potential using fluorescent rhodamine derivatives. Biophys. J. 76:469-477.

32. Chomczynski, P., and Sacchi, N. 1987. Single-step method of RNA isolation by acid guanidinium thiocyanate-phenol-chloroform extraction. Anal. Biochem. 162:156-159.

33. Kim, N.W., and Wu, F. 1997. Advances in quantification and characterization of telomerase activity by the telomeric repeat amplification protocol (TRAP). Nucleic Acids Res. 25:2595-2597.

34. Hirota, Y., Horiuchi, T., and Akahane, K. 1996. p53 antisense oligonucleotide inhibits growth of human colon tumor and normal cell lines. Jpn. J. Cancer Res. 87:735-742.

35. Ceraline, J., et al. 1998. Inactivation of p53 in normal human cells increases $\mathrm{G} 2 / \mathrm{M}$ arrest and sensitivity to DNA-damaging agents. Int. J. Cancer. 75:432-438.

36. Mahdi, T., et al. 1995. In vitro p53 and/or Rb antisense oligonucleotide treatment in association with growth factors induces the proliferation 
of peripheral hematopoietic progenitors. J. Cell Sci. 108:1287-1293.

37. Boirivant, M., et al. 1996. Hypoproliferative human lamina propria T cells retain the capacity to secrete lymphokines when stimulated via CD2/CD28 pathways. Proc. Assoc. Am. Physicians. 108:55-67.

38. Bonhoeffer, S., Mohri, H., Ho, D., and Perelson, A.S. 2000. Quantification of cell turnover kinetics using 5-bromo-2'-deoxyuridine. J. Immunol. 164:5049-5054.

39. Sramkoski, R.M., Wormsley, S.W., Bolton, W.E., Crumpler, D.C., and Jacobberger, J.W. 1999. Simultaneous detection of cyclin B1, p105, and DNA content provides complete cell cycle phase fraction analysis of cells that endoreduplicate. Cytometry. 35:274-283.

40. van den Heuvel, S., and Harlow, E. 1993. Distinct roles for cyclin-dependent kinases in cell cycle control. Science. 262:2050-2054

41. Modiano, J.F., et al. 1995. Symmetry of the activation of cyclin-dependent kinases in mitogen and growth factor-stimulated T lymphocytes. Ann. N. Y. Acad. Sci. 766:134-148.

42. Wei, Y., Yu, L., Bowen, J., Gorovsky, M.A., and Allis, C.D. 1999. Phosphorylation of histone $\mathrm{H} 3$ is required for proper chromosome condensation and segregation. Cell. 97:99-109.

43. Besson, A., and Yong, V.W. 2000. Involvement of p21(Waf1/Cip1) in protein kinase $\mathrm{C}$ alpha-induced cell cycle progression. Mol. Cell. Biol. 20:4580-4590.

44. O'Connor, L., Huang, D.C., O'Reilly, L.A., and Strasser, A. 2000. Apoptosis and cell division. Curr. Opin. Cell Biol. 12:257-263.

45. Symonds, H., et al. 1994. p53-dependent apoptosis suppresses tumor growth and progression in vivo. Cell. 78:703-711.

46. Mayer, L. 1997. Local and systemic regulation of mucosal immunity. Ali- ment. Pharmacol. Ther. 11(Suppl. 3):81-88

47. Duchmann, R., et al. 1995. Tolerance exists towards resident intestinal flora but is broken in active inflammatory bowel disease (IBD). Clin. Exp. Immunol. 102:448-455.

48. Spahn, T.W., et al. 2001. Induction of oral tolerance to cellular immune responses in the absence of Peyer's patches. Eur. J. Immunol. 31:1278-1287.

49. Juan, G., et al. 1998. Histone H3 phosphorylation and expression of cyclins A and B1 measured in individual cells during their progression through G2 and mitosis. Cytometry. 32:71-77.

50. Weinberg, R.A. 1995. The retinoblastoma protein and cell cycle control. Cell. 81:323-330.

51. Bird, J.J., et al. 1998. Helper T cell differentiation is controlled by the cell cycle. Immunity 9:229-237.

52. Wells, A.D., Walsh, M.C., Sankaran, D., and Turka, L.A. 2000. T cell effector function and anergy avoidance are quantitatively linked to cell division. J. Immunol. 165:2432-2443.

53. Pacha, J. 2000. Development of intestinal transport function in mammals. Physiol. Rev. 80:1633-1667.

54. Itoh, J., de La Motte, C., Strong, S.A., Levine, A.D., and Fiocchi, C. 2001. Decreased Bax expression by mucosal T cells favours resistance to apoptosis in Crohn's disease. Gut. 49:35-41.

55. Buckley, A.F., Kuo, C.T., and Leiden, J.M. 2001. Transcription factor LKLF is sufficient to program T cell quiescence via a c-Myc-dependent pathway. Nat. Immunol. 2:698-704.

56. Tzchanis, D., et al. 2001. Tob is a negative regulator of activation that is expressed in anergic and quiescent T cells. Nat. Immunol. 2:1174-1182. 